\title{
Taxonomic notes on the Lispe leucospila species-group (Diptera: Muscidae)
}

\author{
К таксономии Lispe leucospila и родственных видов \\ (Diptera: Muscidae)
}

\author{
N.E. Vikhrev \\ H.E. Buxpeв
}

Zoological Museum of Moscow University, Bolshaya Nikitskaya 6, Moscow, 125009, Russia (ZMMU), corresponding author: Nikita Vikhrev (nikita6510@ya.ru)

Зоологический музей, Московский государственный университет им. М.В. Ломоносова, Большая Никитская ул., 6, Москва 125009 Россия

KEY WORDS: Lispe leucospila, Lispe sinica, Lispe pectinipes, Muscidae, Diptera, key, Palaearctica, Oriental region, new synonym.

КЛЮЧЕВЫЕ СЛОВА: Lispe leucospila, Lispe sinica, Lispe pectinipes, Muscidae, Diptera, ключ, Палеарктика, Ориентальный регион, новый синоним.

ABSTRACT. Synonymy of the Lispe leucospila species-group is considered. In the Palaearctic and the Oriental region this group is represented by two species: Lispe leucospila (Wiedemann, 1830) (= Lispe sinica Hennig, 1960 syn.n. ) and Lispe pectinipes Becker, 1903 (=Lispe leucospila (Wiedemann) sensu Hennig [misidentification]). An identification key for these species and notes on ecology are given. At least one more related species is present in the Afrotropical region.

РЕЗЮМЕ. Рассмотрена группа видов родственных Lispe leucospila (Wiedemann, 1830). В Палеарктике и Ориентальном регионе это группа представлена двумя видами: Lispe leucospila (Wiedemann, 1830) (= Lispe sinica Hennig, 1960 syn.n. ) and Lispe pectinipes Becker, 1903 (=Lispe leucospila (Wiedemann) sensu Hennig [misidentification]). Дан ключ для определения видов и приведены данные по их биологии. Показано, что, по крайней мере, еще один родственный вид представлен в Афротропической области.

\section{Introduction}

Hennig [1960] mentioned L. leucospila (Wiedemann, 1830) among Lispe species not placed in any of the six species-groups he proposed. In this paper I consider a complex of at least 3 related species which I propose to name as Lispe leucospila species-group. The members of this group may be recognized by the following set of characters: palpi moderately dilated; $t 1$ with strong $p$-seta; $t 2$ with $1 p d$ and $1 a d$; 3 with 1 $a d, 1-2 a v$ and in male with several long $p v$ setulae in apical part; prst $d c$ : posterior pair remarkably strong, anterior pair absent; post dc: 2 posterior pairs strong, 1-2 anterior pairs weak.

Based on Stein's examination of the type of $L$. leucospila (Wiedemann) Hennig [1960: 439] came to a conclusion that the vast majority of the available material (from Canary Islands to the Oriental region) belongs to the same widespread species hereinafter referred to as Lispe leucospila sensu Hennig. Hennig examined the type material of Lispe pectinipes Becker, 1903, Lispe cochlearia Becker, 1904 and Lispe mixticia Seguy, 1941 and found them conspecific with Lispe leucospila sensu Hennig. He also revealed 3 female specimens from S-E China differing from others and described them as the new subspecies Lispe leucospila sinica Hennig, 1960.

Later Pont [1986] raised the status of L. leucospila sinica Hennig to the valid species Lispe sinica Hennig.

Lyneborg [1970: 43] examined the type material of L. pectinipes and L. leucospila and found that the male terminalia of the lectotype (designated by Lyneborg [1970: 43] of L. pectinipes (Fig. 2) were similar to the Hennig's drawing given for L. leucospila sensu Hennig (Fig.1) [Hennig, 1960: plate XX, Fig. 399 and Textfig. 154], but the male terminalia of the lectotype (designated by Lyneborg [1970: 44]) of L. leucospila were different (Fig. 3). So, Lyneborg restored L. pectinipes Becker as a valid species. Lyneborg identified his material belonging to the Lispe leucospila species-group from Spain and Algeria as L. pectinipes.

Pont [1991] examined the Lispe leucospila speciesgroup material from Arabian Peninsula. Again, no specimen with male terminalia fitting the lectotype of $L$. leucospila was recorded at all and the majority of specimens were identified as L. pectinipes, but $1 \sigma^{\top}$ and 2 ㅇ from Yemen were identified as Lispe sp. 
1 Lispe leucospila Wied, sensu Hennig

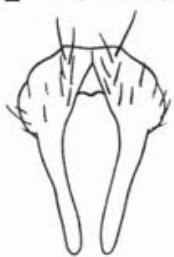

cp

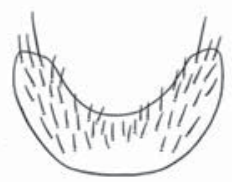

st 5

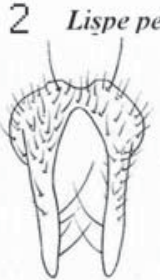

cp

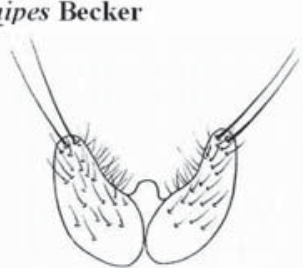

st 5

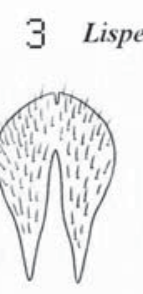

cp

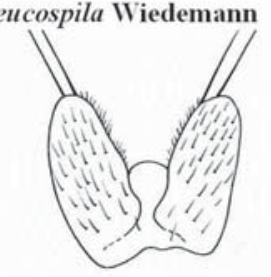

$\mathrm{st} 5$

Figs 1-3. Male terminalia of Lispe leucospila (Wiedemann) sensu Hennig (1), L. pectinipes Becker (2) and L. leucospila (Wiedemann) (3): 1 - from [Hennig, 1960: plate XX, Fig. 399 and Textfig. 154]; 3 - from Lyneborg, 1970: 43. Abbreviations: cp — cercal plate in posterior view; st5 - sternite 5 .

Рис. 1-3. Терминалии самцов Lispe leucospila (Wiedemann) sensu Hennig (1), L. pectinipes Becker (2) и L. leucospila (Wiedemann) (3): 1 - по Hennig, 1960: plate XX, Fig. 399 and Textfig. 154; 3 - по [Lyneborg, 1970: 43. Сокращения: ср - церки вид сзади; st5 - 5-й стернит.

Meanwhile Asian authors still use the name L. leucospila in the sense of L. leucospila sensu Hennig, see for example Shinonaga \& Tewari [2008] or Xue \& Zhang [2005], the other species from this group recorded by Asian authors is L. sinica Hennig.

So, the main question was: what is L. leucospila apart from Wiedemann's syntypes. I hope that in this paper I clarify the situation.

\section{Taxonomic part}

The specimens studied are in the Zoological Museum of Moscow University (unless otherwise indicated in text).

Lispe leucospila (Wiedemann, 1830)

(Figs 3, 4, 5)

Coenosia leucospila Wiedemann, 1830: 441. Type locality: “Ostindien"; lectotype $\sigma^{7}$ and paralectotypes $2+0$, Universitetets Zoologisk Museum, Copenhagen, designated by Lyneborg, 1970: 44

Lispe leucospila sinica Hennig, 1960: 440, syn.n.

Lispe sinica: Pont, 1986.

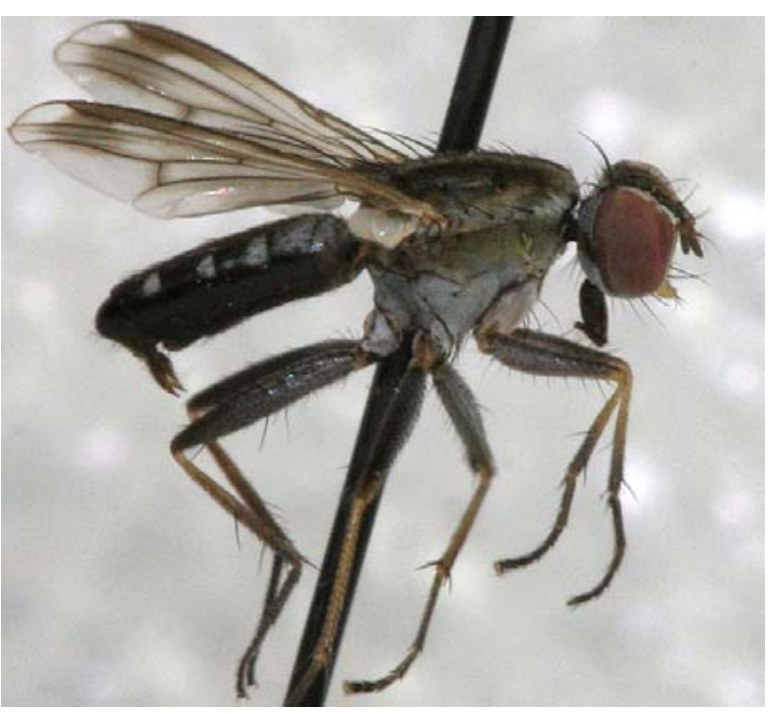

Fig. 4. Lispe leucospila Wiedemann, male.

Рис. 4. Lispe leucospila Wiedemann, самец.
Lispe leucospila (Wiedemann, 1830): Lyneborg, 1970: 43, Figs. 23, 24, 25.

MATERIAL EXAMINED. China: (Laoning prov.), Mukden (Shenyang), 12.VII.1952, I.Rubtsov, 2 우 - Zoological Institute S-Petersburg, paratypes Lispe leucospila sinica Hennig, 1960: 440; Cambodia: Kampot prov, Bokor, $1000 \mathrm{~m}$ asl., $10.627^{\circ} \mathrm{N} 104.026^{\circ} \mathrm{E}$, 08-10.XII.2010, N.Vikhrev, $1 \sigma^{7}$; Koh Kong prov, a wet grassland, $11.660^{\circ} \mathrm{N} 103.097^{\circ} \mathrm{E}, 29 . X I .2010$, N.Vikhrev, $4 \sigma^{\top} \sigma^{\top}, 7$ 9o; Thailand: Chonburi prov., Jomtien env., X. 2007-2009, N.Vikhrev, 3 $\sigma^{\top} \sigma^{\top}, 6$ 우 ; Phang Nga prov., Khao Lak env., $8.65^{\circ} \mathrm{N} 98.25^{\circ} \mathrm{E}$, 20.XII.2010, N.Vikhrev, 1 \%; India: Goa state, 15.II.2009,

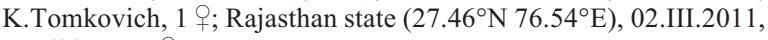
N.Vikhrev, 1 ㅇ․

\section{Lispe pectinipes Becker, 1903 \\ Figs 1, 2, 5.}

Lispa pectinipes Becker, 1903: 113. Type locality: Egypt, Cairo; lectotype $\sigma^{7}$ and paralectotypes 2 우, Zoologisches Museum der Humboldt-Uneversitat, Berlin, designated by Lyneborg, 1970: 43.

Lispa cochlearia Becker, 1904: 32

Lispa mixticia Seguy, 1941: 1.

Lispe leucospila (Wiedemann, 1830) sensu Hennig [1960: 440, plate XX, Fig. 399 and Textfig. 154], misidentification.

Lispe pectinipes Becker, 1903, Lyneborg, 1970: 43, Figs. 20, 21, 22.

MATERIAL EXAMINED. Over 80 specimens from: Morocco (Essaouira), Greece (Crete), Egypt (Luxor), Turkey (Izmir, Antalia,

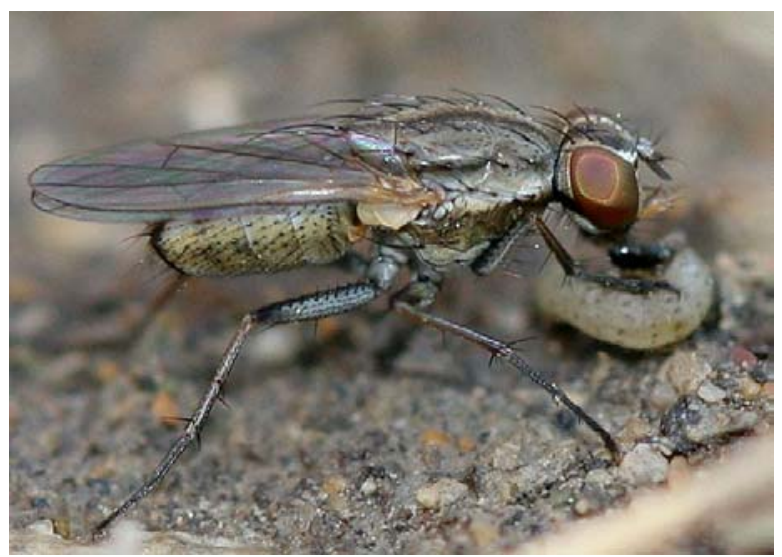

Fig. 5. Lispe pectinipes Becker. Female with prey — insect larva, Turkey.

Рис. 5. Lispe pectinipes Becker. Самка с добычей — личинкой насекомого, Турция. 


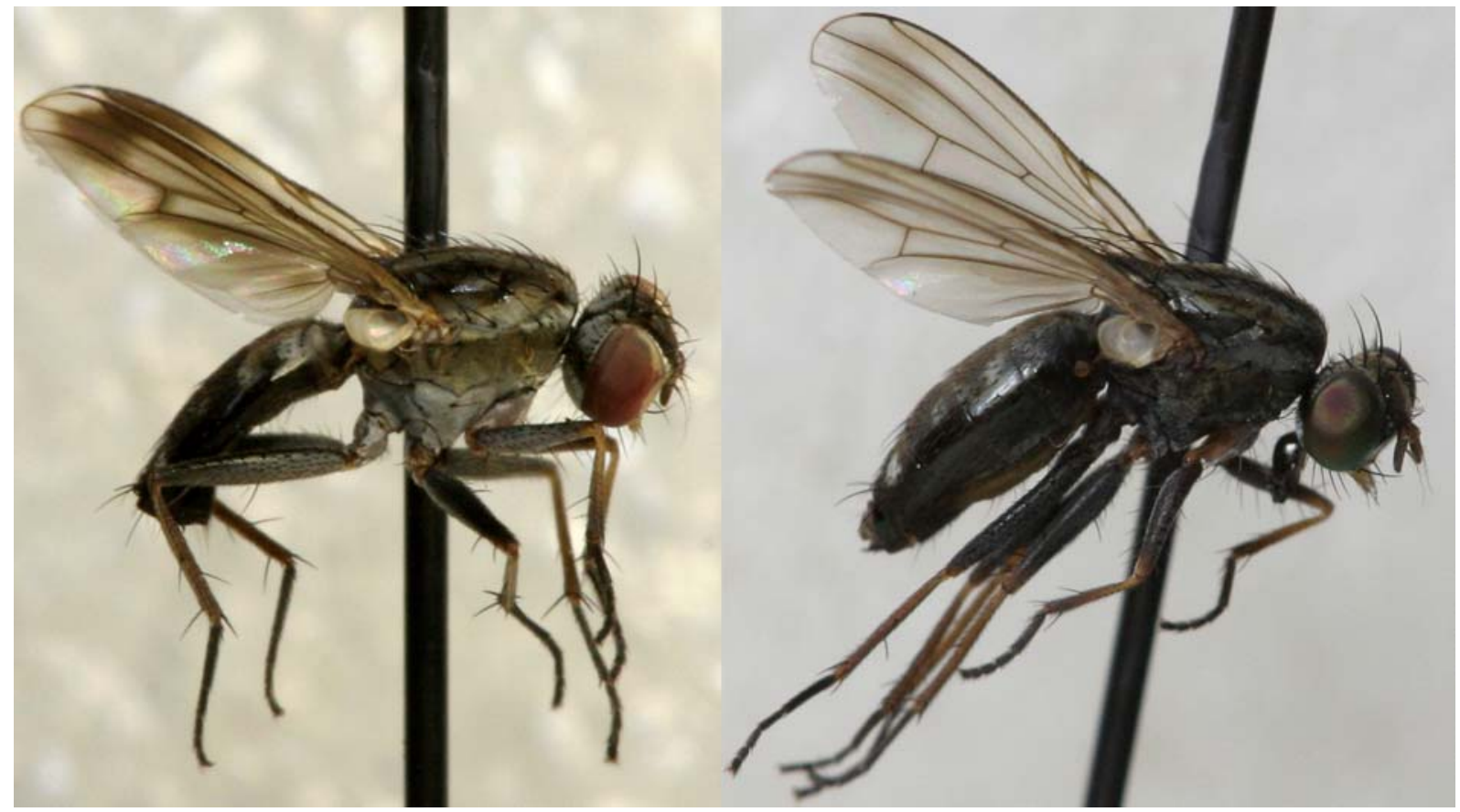

Fig. 6. Fresh (left) and aged (right) females of Lispe leucospila Wiedemann.

Рис. 6. Молодая (слева) и старая (справа) самки Lispe leucospila Wiedemann.

Konya, Hatay), Azerbaijan (Lenkoran), India (Goa, Rajasthan), Thailand (Chonburi, Chantaburi, Mae Hong Son, Phang Nga).

\section{Lispe sp.}

Lispe sp. of leucospila-group. Pont, 1990: 354, Figs. 18, 19. MATERIAL EXAMINED. Ethiopia: Oromia reg., $8.057 \mathrm{~N}$ 38.007E, savannah, 01.XI.2009, L.Rybalov, 1 O'; Yemen: Taiz, banana plantation, 24.I.1975, Sakharova, 1 .

IDENTIFICATION KEY FOR THE LISPE LEUCOSPILA SPECIESGroup (For PalaeArctic AND ORIENTAL REgions)

- $O^{7}$ : Abdomen with a lateral uninterrupted grey stripe on tergites $1+2$ to 5 ; ; : Abdomen densely grey dusted, only dorsally with black spots. $\sigma^{7} O_{+}$: Disc of scutum densely dusted, with rather narrow brown median vitta from neck to tip of scutellum, submedian vittae hardly distinct. Two proepisternal setae (the second one half as long as the first one). Wing hyaline. $\sigma^{7}$ : frontal triangle dusted, $t 3$ with 8-11 longer $p v$ setae. S-W and S-E Palaearctic, Oriental, (Afrotropical?) ........ pectinipes Becker

- $\sigma^{7}+$ : Abdomen entirely glossy black, only small paired white dorso-lateral spots present (spots on tergites 4 and 5 always widely separated by glossy area in males, in females these spots sometimes are reduced up to a single pair on tergite 5 only). Disc of scutum dusted only in lateral part, with rather wide, glossy black, distinct median and submedian vittae, disc of scutellum entirely glossy black. Only one proepisternal seta (if the second one present it is usuallyhardly longer than scutal ground setulae). Wing darkened as in Fig. 4 and 6. (sometimes hardly visible). $O^{7}$ : Frontal triangle undusted black in central part. $t 3$ with 5-6 shorter $p v$ setae. Oriental, S-E Palaearctic leucospila Wiedemann

\section{Discussion}

1. I propose the synonymy of $L$. leucospila sensu Hennig with $L$. pectinipes which follows from the results published by Lyneborg [1970], but was never formally proposed. Hennig regarded $L$. pectinipes and L. leucospila sensu Hennig as synonyms; the male terminalia of L. pectinipes given by Lyneborg (Fig. 2) are similar to Hennig's drawing for L. leucospila sensu Hennig (Fig. 1) and to the male terminalia of L. pectinipes from Morocco, Egypt, Turkey and Thailand examined by me; other characters of my specimens of $L$. pectinipes also completely fit Hennig's description of L. leucospila sensu Hennig. L. leucospila sensu Shinonaga et sensu Xue actually is L. pectinipes too.

2. The female specimens listed above as L. leucospila completely fit Hennig's description of Lispe leucospila sinica and are similar to the female paratype of L. leucospila sinica in ZIN. On the other hand, the male specimens listed above as L. leucospila have the terminalia similar to those given for the lectotype of $L$. leucospila by Lyneborg [1970]. Lyneborg has also mentioned that the lectotype of $L$. leucospila has the abdominal pattern on tergites 4 and 5 differing from that of L. pectinipes. At the same time the abdominal pattern on tergites 4 and 5 of the lectotype of L. leucospila and of my specimens fits that of $L$. sinica.

The question arises why Lyneborg did not mention the scutal pattern and wing darkening? The scutum is often damaged by a pin and besides this character requires a good condition of specimens which is a rare 
case for flies collected almost two hundred years ago. Wing darkening in L. leucospila seems to be nonpersistent (probably light-sensitive), Fig. 5 shows that the wing pattern is hardly visible in an aged specimen in comparison with a fresh one. I suppose that the instability of wing pattern leads to similar effects in aged specimens and in those collected long ago. What is more, Fig. 6 illustrates that scutal pattern becomes poorly visible in aged specimens too, so that the abdominal pattern is the most reliable character and it is placed as the main one in the identification key.

Thus, both in the Palaearctic and the Oriental regions the Lispe leucospila species-group is represented by two easily recognizable species: the more common and widespread L. pectinipes and the less common although earlier described L. leucospila.

The male from Ethiopia completely fits Pont's [1991] description of Lispe sp. from Yemen, but the correct naming of this species requires examination of additional Afrotropical material.

\section{Ecology}

Both L. leucospila and L. pectinipes differ ecologically from most of other Lispe: their typical habitats are grassy lawns being artificially watered or similar natural habitats, usually secondary sites with short grass and moderately wet soil. In the southern Palaearctic these conditions are usually present in the cold season from late autumn to early spring and in the Oriental region after the end of rainy season. The best way of collecting is by sweeping in the evening when flies sit on grass and are not too active. The typical prey items are insect larvae (Fig. 5).

ACKNOWLEDGEMENTS. I thank Oleg Kosterin (Novosibirsk) who suggested very useful corrections.

\section{References}

Hennig W. 1955-1964. Family Muscidae // Lindner E. (ed.). Die Fliegen der Paläarktischen Region 63b. Stuttgart. $1110 \mathrm{~S}$.

Lyneborg L. 1970. Some Muscidae from southern Spain, with descriptions of six new species (Insecta, Diptera) // Steenstrupia. Vol.1. No.6. P.29-54.

Pont A.C. 1986. Family Muscidae // Soos A., Papp L. (eds.). Catalogue of Palaearctic Diptera. Budapest. Vol.11. P.57-215.

Pont A.C. 1991. A review of the Fanniidae and Muscidae of the Arabian Peninsula. Fauna of Saudi Arabia. Vol.12. P.312365.

Shinonaga S., Tewari R.R. 2008. Record of the Muscid flies collected in India, Sri Lanka and Bangladesh (Diptera, Muscidae) // Japanese Journal of Systematic Entomology. Vol.14. No.2. P.205-251.

Xue W.-Q., Zhang D. 2005. A review of the genus Lispe Latreille (Diptera: Muscidae) from China, with descriptions of new species // Oriental Insects. Vol.39. P.117-139. 